\title{
Proton Transfer Equilibria and Critical Behavior of H-Bonding
}

\author{
L. Sobczyk, B. Czarnik-Matusewicz, M. Rospenk, and M. Obrzud
}

Faculty of Chemistry, University of Wrocław, Joliot-Curie 14, 50-383 Wrocław, Poland

Correspondence should be addressed to L. Sobczyk, lucjan.sobczyk@chem.uni.wroc.pl

Received 23 February 2012; Revised 25 April 2012; Accepted 26 April 2012

Academic Editor: Marek J. Wojcik

Copyright ( 92012 L. Sobczyk et al. This is an open access article distributed under the Creative Commons Attribution License, which permits unrestricted use, distribution, and reproduction in any medium, provided the original work is properly cited.

\begin{abstract}
The aim of the present paper is an analysis of the hydrogen bond properties for the acid-base systems depending on the ability to the proton transfer in the formulation of the Brönsted approach. After definition of the proton transfer equilibrium expressed by using the equation $\log K_{\mathrm{PT}}=\xi \Delta p K_{N}$, various examples of different physical properties, such as dipole moments, IR spectra, and nuclear magnetic resonances, are presented which correlate with the $\Delta p K_{N}$ value. In such a way, a critical state of hydrogen bonding can be defined that corresponds to the potential of the proton motion for either single minimum or double minimum with low barrier. A particular attention in this paper found electronic spectra which have not been analysed so far and the quantitative analysis of the vibrational polarizability which can reach very high values of the order of electronic polarizability.
\end{abstract}

\section{Introduction}

The subject of our interest in the present review is hydrogen bonds which can be expressed as A-H . B. It is an acid-base system in the Brönsted formulation when the $\mathrm{A}-\mathrm{H}$ group is treated as an acid while the $\mathrm{B}$ atom or group of atoms as proton acceptor (base). The potential energy curves for the proton motion can reach various shapes, as shown in Figure 1.

The extreme curves (1) and (6) correspond to states either without proton transfer (1) or to the complete ionization when the proton is attached to $\mathrm{B}$ while atom $\mathrm{A}$ is negatively charged (6). Among the intermediate states take place those when the proton is located in the central position either with two minima (3) and a low barrier or with one single minimum (4).

There is a rich literature [1-16] with various approaches to the hydrogen bonding corresponding to different definitions, showing an increase of systems analyzed with comprehensive theoretical treatments, and containing different rich chemical characteristic features of hydrogen bonds. Most actual comprehensive review was recently published by G. Gilli and P. Gilli [16].

From the point of view of the approach based on the acid-base interaction, the substantial, parameter is the proton transfer degree which evokes changes of further physico-chemical parameters. The main quantity is the $\Delta p K_{a}$ value which can be expressed in the form:

$$
\Delta p K_{a}=p K_{\mathrm{B}^{+} \mathrm{H}}-p K_{\mathrm{AH}} .
$$

This quantity was introduced by Huyskens and ZeegersHuyskens [17]. We introduced normalized parameter defined as

$$
\Delta p K_{N}=\Delta p K_{a}-\Delta p K_{a}(\mathrm{crit}),
$$

where $\Delta p K_{a}$ (crit) is related to $\Delta p K_{a}$ region when the proton transfer degree reaches $50 \%$ [18].

The dependence of proton transfer degree on the $\Delta p K_{N}$ value needs a correction connected with "softness/hardness" of interaction by using parameter $\xi<1$ [19]. The value of this parameter is the higher, the harder is the interaction reaching maximal value equal to unity. As will be seen, this quantity is well correlated with the polarizability in the transition state of hydrogen bonds. The general equation presenting the dependence of proton transfer degree on $\Delta p K_{N}$ possesses the form:

$$
\log K_{\mathrm{PT}}=\xi \Delta p K_{N} .
$$

One should remember that physicochemical parameters measured depending on $\Delta p K_{N}$ and connected with the 

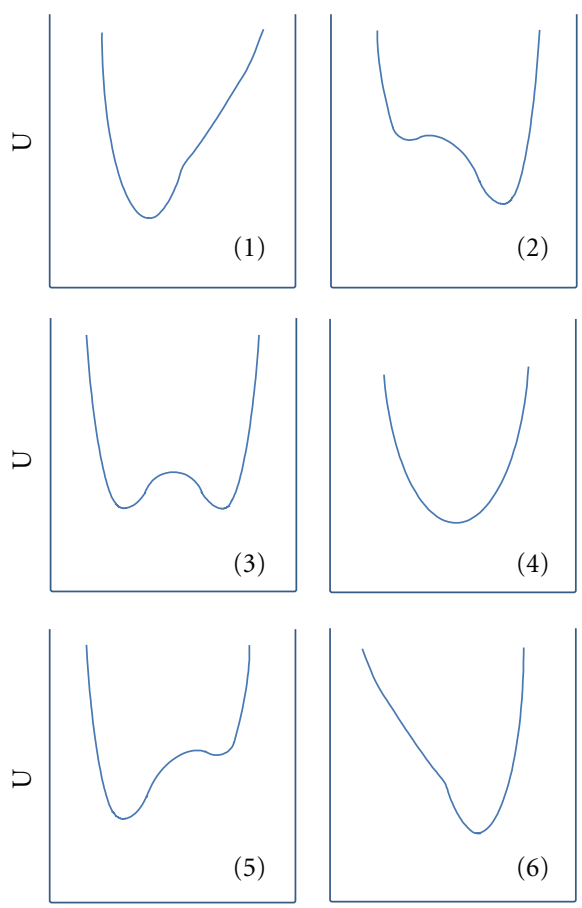

Proton motion

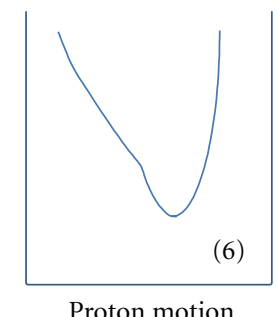

Proton motion

Figure 1: Postulated potential energy curves for the proton motion starting from nonproton-transfer state (1) up to fully ionized state (6).

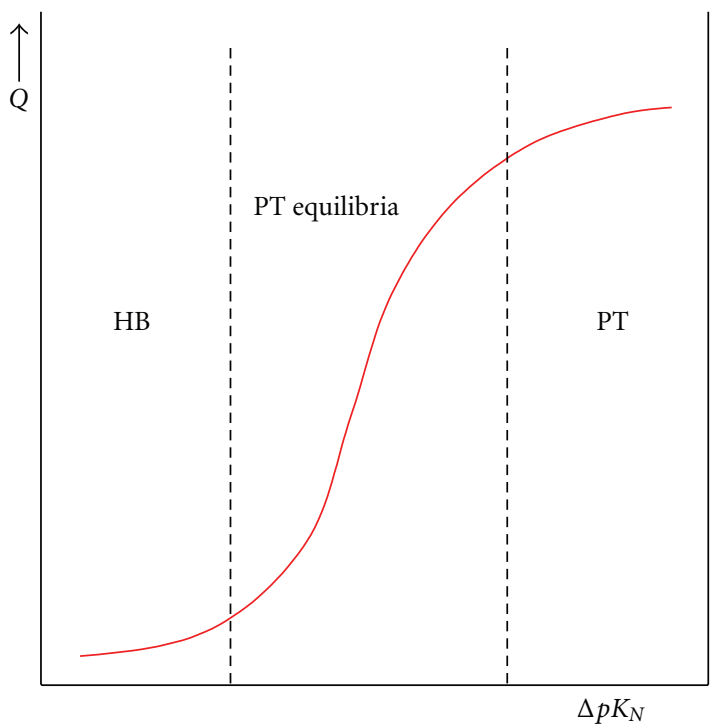

FIGURE 2: Three regions of physical properties depending on $\Delta p K_{N}$ : HB-related to nonproton-transfer states, PT-related to proton transfer state and $\mathrm{HB}+\mathrm{PT}$ proton transfer equilibrium.

softness of interaction are related not only to $\Delta p K_{N}$ as has been shown in Figure 2.

There exist three regions; the central one with the equilibria of the proton transfer and side regions without proton transfer $(\mathrm{HB})$ and with full ionization $(\mathrm{PT})$.

Finally, as will be shown, it is necessary to mention the role of medium such as electric permittivity of the solvent

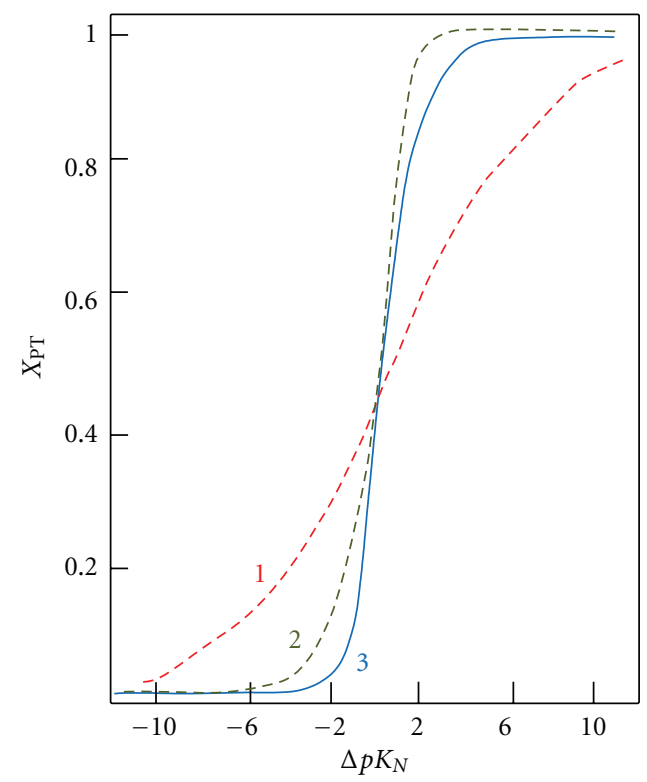

FIgure 3: Proton transfer degree from NQR measurements for complexes composed of chlorine containing proton donors plotted versus $\Delta p K_{N}$ : (1) $\mathrm{CCl}_{3} \mathrm{COOH}$ complexes $(\xi=0.12)$, (2) $\mathrm{CHCl}_{2} \mathrm{COOH}$ complexes $(\xi=0.42)$, and $(3) \mathrm{C}_{6} \mathrm{Cl}_{5} \mathrm{OH}$ complexes $(\xi=0.74)[20]$.

and specific interaction between the solute and solvent molecules.

For characterization of the role of the $\xi$ parameter we present in Figure 3 dependencies of the proton transfer degree deduced from the measurements of nuclear quadruple resonance (NQR) for complexes of $\mathrm{CCl}_{3} \mathrm{COOH}$ (1) $(\xi=$ $0.12), \mathrm{CHCl}_{2} \mathrm{COOH}(2)(\xi=0.42)$, and $\mathrm{C}_{6} \mathrm{Cl}_{5} \mathrm{OH}(3)(\xi=$ 0.74 ) [20]. It is well seen the property of the curves in the critical region when approaching to $\Delta p K_{N}=0$.

It is justified to mention in the introduction that curves expressing dependencies of physicochemical parameters on $\Delta p K_{N}$ possess various shapes [18]. One can distinguish two types of correlations between the physical quantity and $\Delta p K_{N}$, namely, of the sigma and delta type. The examples of such correlations will be presented in the next chapter.

\section{Examples of Correlation between Physicochemical Parameters and the $\Delta p K_{N}$ Quantity}

So far a most precisely investigated phenomenon is the dependence of the increase of dipole moment $\Delta \mu$ for complexes of phenols with N-bases. In Figure 4, we present correlation between $\Delta \mu$ and $\Delta p K_{N}$ obtained for a number of systems in nonpolar solvents, particularly in benzene [18]. The experimental points are adjusted to the equation [21]:

$$
\begin{aligned}
\Delta \mu= & \frac{\Delta \mu_{\mathrm{HB}}+b_{\mathrm{HB}} \Delta p K_{N}}{1+\exp \left(2.303 \xi \Delta p K_{N}\right)} \\
& +\frac{\left(\Delta \mu_{\mathrm{PT}}+b_{\mathrm{PT}} \Delta p K_{N}\right) \cdot \exp \left(2.303 \xi \Delta p K_{N}\right)}{1+\exp \left(2.303 \xi \Delta p K_{N}\right)},
\end{aligned}
$$




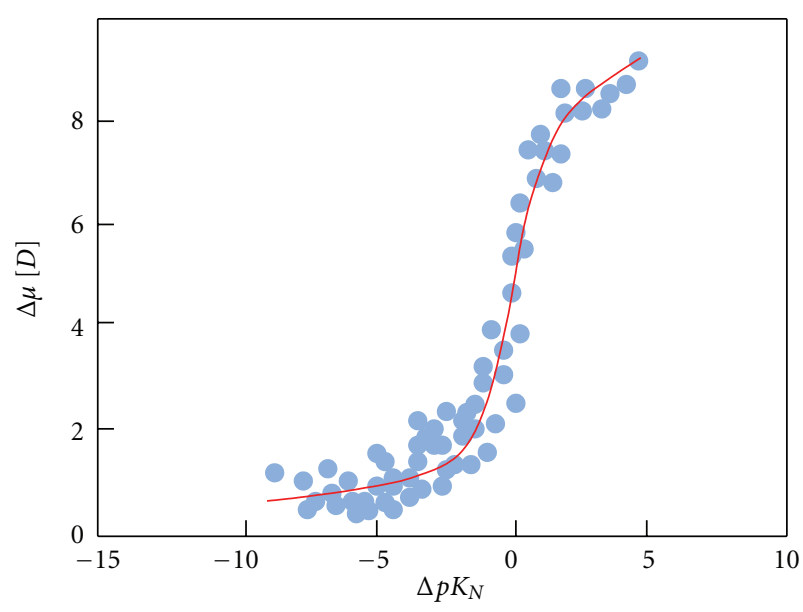

Figure 4: The increase of dipole moment $\Delta \mu$ plotted versus normalized parameter $\Delta p K_{N}[18]$.

where $\Delta \mu_{\mathrm{HB}}$ and $\Delta \mu_{\mathrm{PT}}$ mean the increase of the dipole moment without proton transfer (HB) and after the proton transfer (PT). These quantities depend nearly linearly on $\Delta p K_{N}$ with coefficients $b_{\mathrm{HB}}$ and $b_{\mathrm{PT}}$. When approaching the critical region around $\Delta p K_{N}=0$, a stepwise change of the dipole moment connected with the increase of the proton degree takes place. The proton transfer degree $x_{\mathrm{PT}}$ defines the equilibrium:

$$
X_{\mathrm{PT}}=\frac{\exp \left(2.303 \xi \Delta p K_{N}\right)}{1+\exp \left(2.303 \xi \Delta p K_{N}\right)} .
$$

To obtain the agreement with the experiment, it is necessary to introduce the coefficient $\xi$ which, as has been formulated, characterizes softness/hardness of interactions. It can be, on the other hand, connected with the barrier height for the proton transfer. The value of the $\xi$ coefficient for the case of the situation in Figure 4 equals 0.65 .

Very similar run of the dependence on $\Delta p K_{N}$ shows the value of the ${ }^{15} \mathrm{~N}$ resonance chemical shift with the $\xi$ value equal to 0.56 [22]. However, one should remember that the results are related to markedly different experimental conditions. Thus, the results obtained for ${ }^{15} \mathrm{~N}$ chemical shift were obtained for complexes of carboxylic acids with pyridine in liquefied freons.

Sigmoidal type of the relationship of physical quantity on $\Delta p K_{N}$ is also observed for complexes of pentachlorophenol with amines by using the nuclear quadrupole resonance (NQR) [23] that is presented in Figure 5. In addition to experimental points, there are indicated values corresponding to neat pentachlorophenol, H-bis-phenolate, as well as to $\mathrm{Na}^{+}$and tributylamine salts. One should remember that NQR measurements are performed for solid state that reflects observed behavior.

The similar shape of the plot with that in Figure 5 is observed between geometrical parameters of complexes and $\Delta p K_{N}$ and particularly between $\mathrm{C}-\mathrm{O}$ bond length and $\Delta p K_{N}$ [25].

An example of correlation between the measured quantity and $\Delta p K_{N}$ of the delta type relates first of all to the proton magnetic resonance $\delta^{1} \mathrm{H}$. It is presented for the

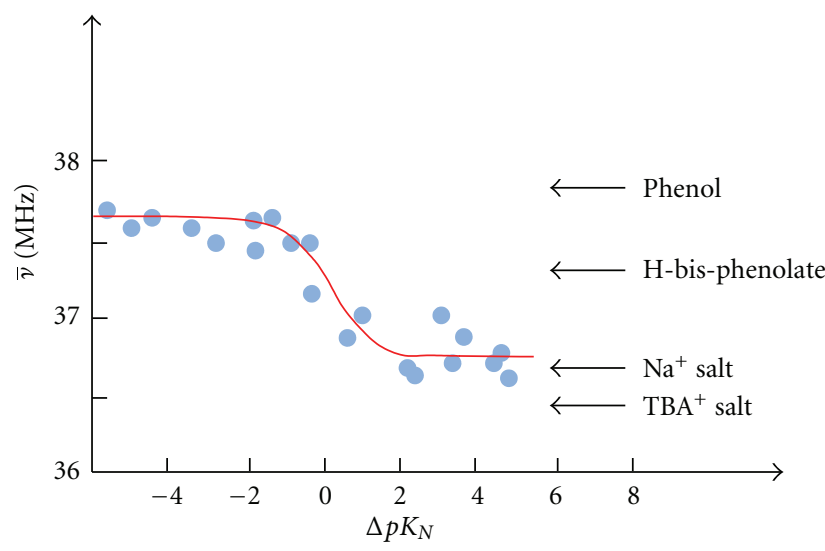

FIgure 5: The dependence of average $\mathrm{NQR}{ }^{35} \mathrm{Cl}$ frequency upon $\Delta p K_{N}$ for complexes of pentachlorophenol [24].

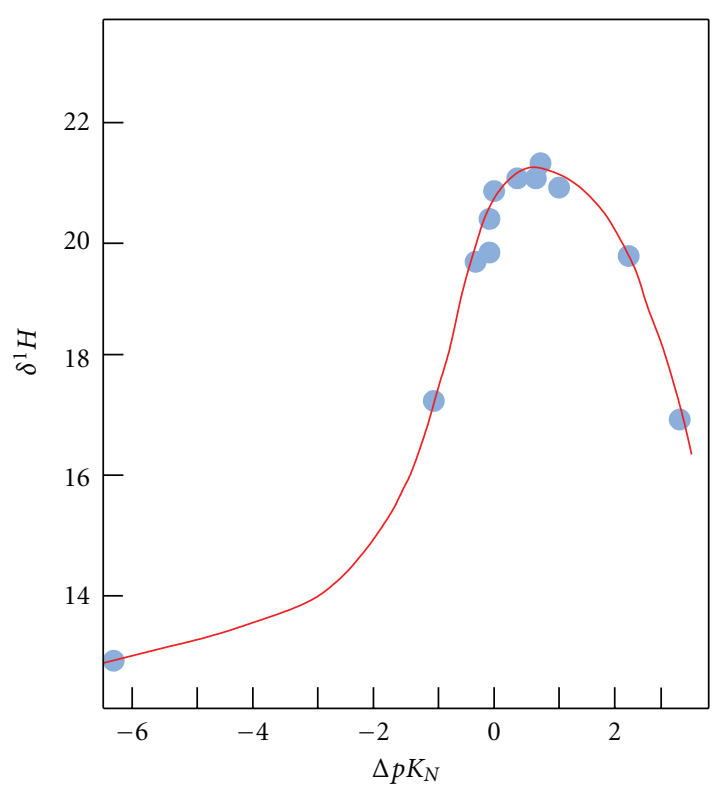

FIGURE 6: The dependence of $\delta^{1} \mathrm{H}$ for complexes of carboxylic acids with pyridine in liquid freon [22].

systems analogues to the $\delta^{15} \mathrm{~N}$ resonance [18]. The experimental points of $\delta^{1} \mathrm{H}$ presented in Figure 6 were obtained in the same conditions as for $\delta^{15} \mathrm{~N}$. The value of the $\xi$ parameter is, however, somewhat lower $(0.46)$ that we are not able to explain. From already done numerous experiments it follows that methods applied do not possess marked influence on the $\xi$ value.

In the analysis of the correlation plots exhibiting an extremum in the critical region as in the case of $\delta^{1} \mathrm{H}$, a modified approach can be used. Thus, for the description of the dependence of given physical property $Q$ showing an extremum, the following simple procedure can be employed. The reference value of a given physical property $Q$ is its extremum; that is, maximum or minimum. In the case of $\delta^{1} \mathrm{H}$ for the systems composed of carboxylic acids and pyridine in liquid freons the maximum value equals $21.5 \mathrm{ppm}$. The delta type correlation can be transformed to the sigmoidal one by assuming that $Q$ (crit) $=0$, while $\Delta Q_{\mathrm{HB}}<0$ and $\Delta Q_{\mathrm{PT}}>0$ as has been done in Figure 7. 


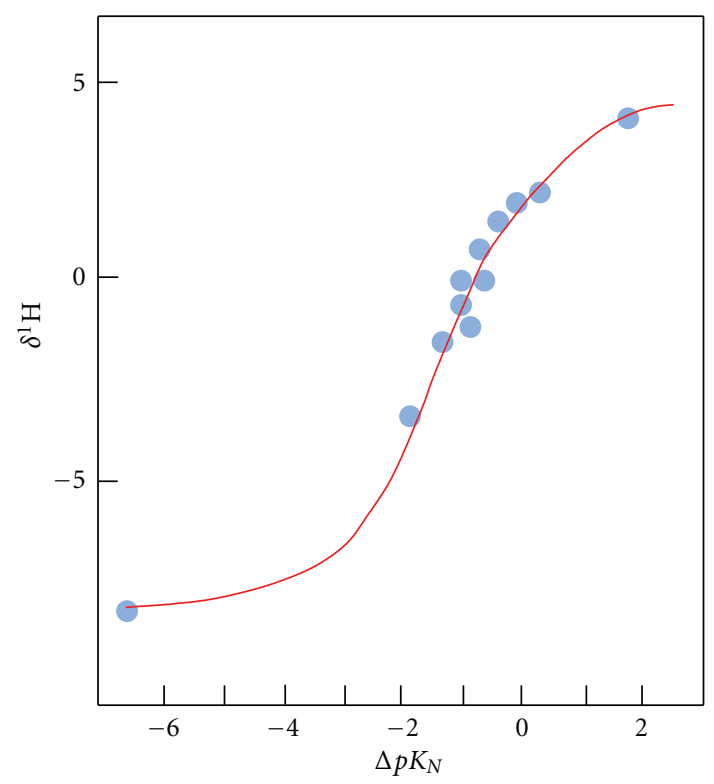

Figure 7: Correlation between $\delta^{1} \mathrm{H}$ and $\Delta p K_{N}$ for complexes of carboxylic acids with pyridine in liquid freon according (6).

The correlation between $\Delta Q$ and $\Delta p K_{N}$ is presented in the following equation [18]:

$$
\Delta Q=\frac{\Delta Q_{\mathrm{HB}}+\Delta Q_{\mathrm{PT}} \exp \left(2.303 \xi \Delta p K_{N}\right)}{1+\exp \left(2.303 \xi \Delta p K_{N}\right)} .
$$

The parameters for best fitting are $Q_{\max }=21.5 \mathrm{ppm} \Delta Q_{\mathrm{HB}}=$ $-8.3 \mathrm{ppm}$ while $\Delta Q_{\mathrm{PT}}=4.4 \mathrm{ppm}$ and $\xi=0.46$ as has been already mentioned.

The properties of infra-red spectra are commonly accepted for the hydrogen bonded systems. This relates first of all to the absorption band ascribed to the stretching vibrations of either $\mathrm{AH}$ group ( $\mathrm{HB}$ state) or $\mathrm{BH}^{+}$group (PT state). The evolution of broad absorption ascribed to the $v(\mathrm{AH})$ or $v\left(\mathrm{NH}^{+}\right)$vibrations is illustrated in Figure 8 taking as an example complexes of pentachlorophenol with amines [26]. In the infra-red spectra the correlated quantity is the center of gravity of protonic vibrations $\left(\nu_{\mathrm{cg}}\right)$ versus the $\Delta p K_{N}$ value. Figure 9 represents numerous data related to $v_{\mathrm{cg}}$ collected for various $\mathrm{O}-\mathrm{H} \cdots \mathrm{N}$ hydrogen bridges [27]. The scattering of experimental points is very large that seems to be understandable taking into account various experimental conditions and differences in the acid-base interaction for various components. One of the reasons of scattering is a difficulty connected with precise assessment of the position of broad bands. As follows from the results collected by Albrecht and Zundel [28] for the complexes of phenols with octylamine, the maximal absorbance in the range of continuous absorption corresponds to $50 \%$ of proton transfer that is shown in Figure 10.

\section{Electronic Spectra and the Proton Transfer Degree}

The UV-Vis spectroscopy is a very useful method of studies on the proton transfer degree in the Brönsted acid-base

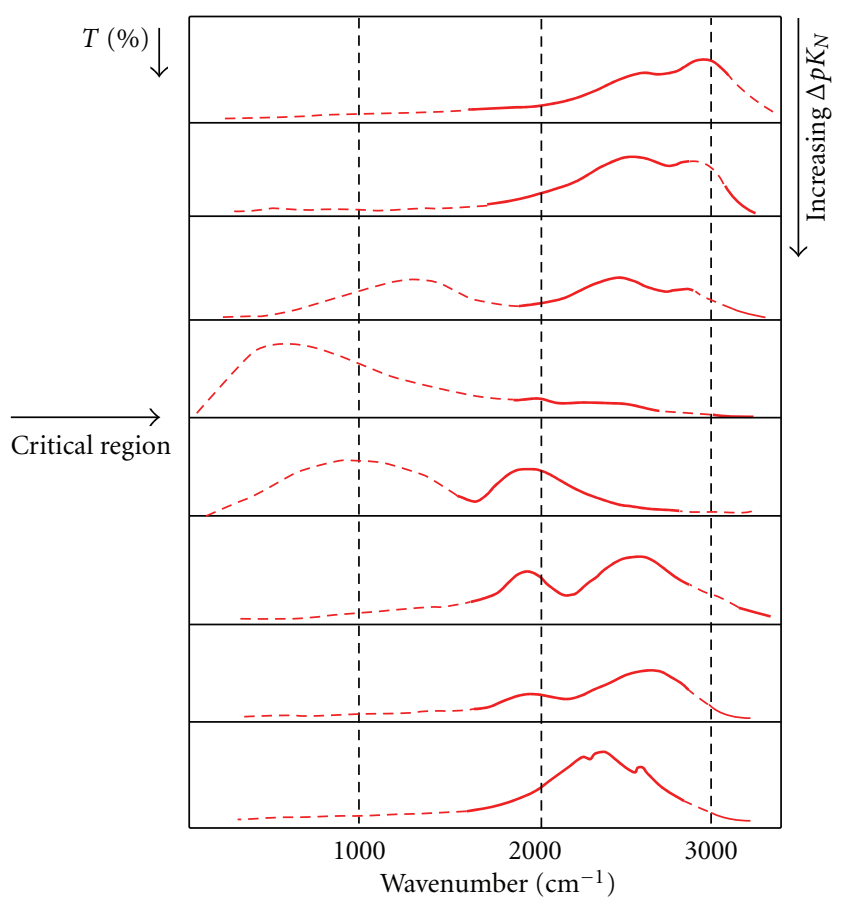

FIGURE 8: The evolution of infra-red absorption ascribed to $v(\mathrm{OH})$ when increasing $\Delta p K_{N}$ for complexes of pentachlorophenol with amines [26].

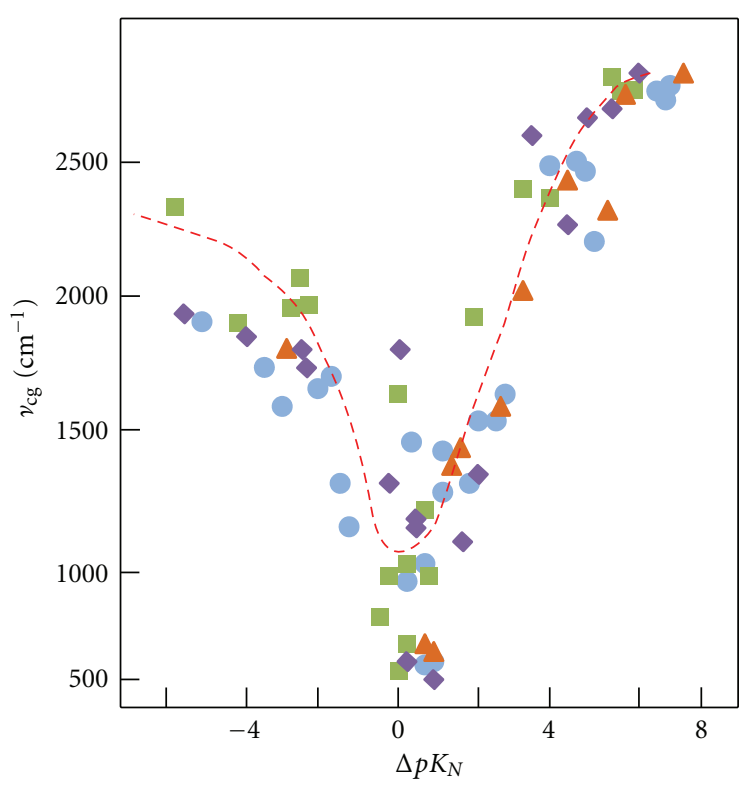

FIGURE 9: The center of gravity $\nu_{\mathrm{cg}}$ for protonic vibrations as a function of $\Delta p K_{N}$ for various complexes of carboxylic acids [27].

system for the diluted solutions. The majority of quantitative data related to the proton transfer equilibria relates mainly to the complexes between phenols and amines [24, 29-35]. In the UV spectra, the tautomeric equilibrium is characterized by appearance of a new band corresponding to the $\pi \rightarrow \pi^{*}$ transition in the phenolate ion. After careful quantitative separation of the $\mathrm{HB}$ and $\mathrm{PT}$ bands the proton transfer equilibrium $c_{\mathrm{PT}} / c_{\mathrm{HB}}$ can be evaluated. As an example of the UV spectra with the proton transfer equilibrium, we use 


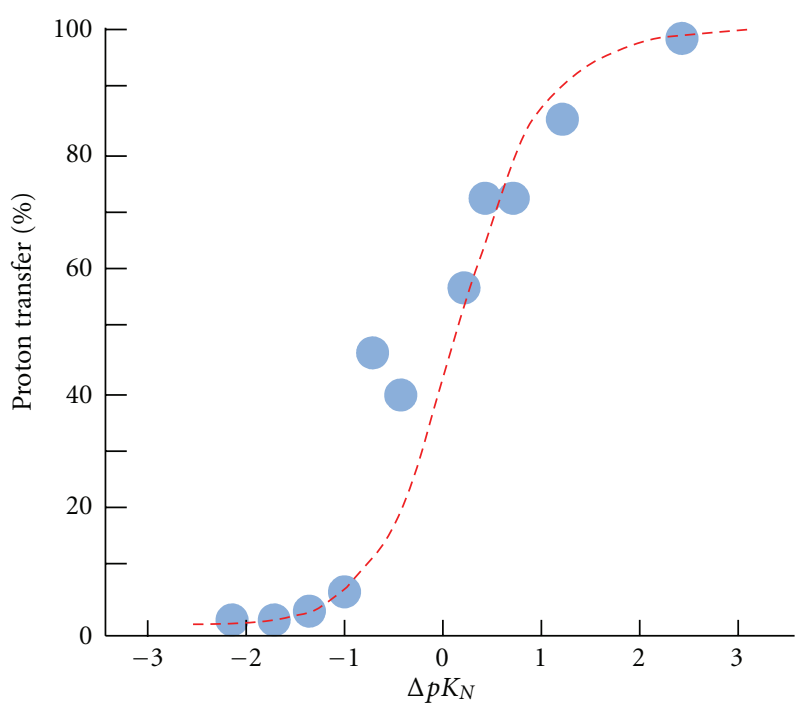

(a)

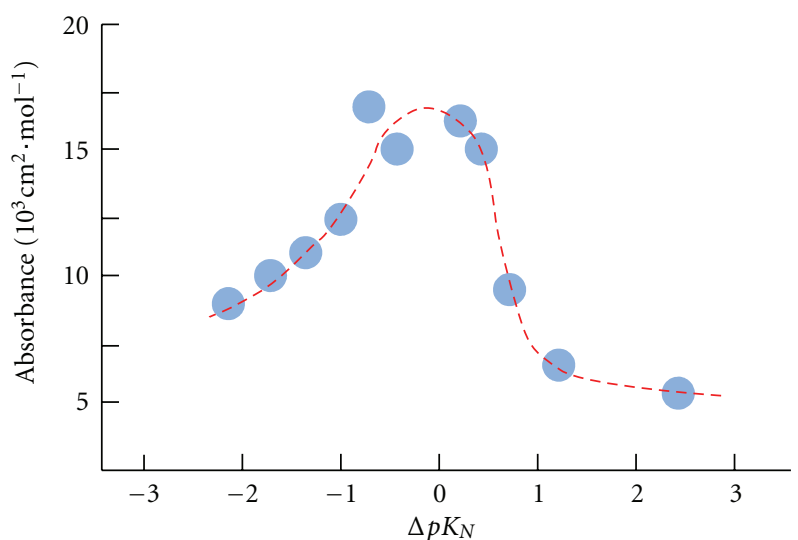

(b)

FIGURE 10: The proton transfer degree (a) and intensity of continuous absorption (b) for complexes of phenols with octylamine [28].

the system of 2,4,6-trichlorophenol in tributylamine (TBA) [29] presented in Figure 11 which shows the overlapping of HP and PT bands. From the equilibrium constant, other thermodynamic parameters can be determined according to equation:

$$
\ln K=\frac{\Delta S^{\circ}}{R}-\frac{\Delta H^{\circ}}{R T},
$$

where $K$ is calculated by using intensities of bands and molar absorption coefficients of corresponding forms:

$$
K=\left(\frac{I_{\mathrm{PT}}}{I_{\mathrm{HB}}}\right)\left(\frac{\varepsilon_{\mathrm{HB}}}{\varepsilon_{\mathrm{PT}}}\right) .
$$

The first quantitative studies by using the electronic absorption spectra were performed by Baba et al. [30] for complex of 4-nitrophenol with triethylamine in 1,2dichloroethane who found $\Delta H^{\circ}=-13 \mathrm{~kJ} \cdot \mathrm{mol}^{-1}$ and $\Delta S^{\circ}=$ $-49.8 \mathrm{~J} \cdot \mathrm{mol}^{-1} \cdot \mathrm{K}^{-1}$. Similarly, Crooks and Robinson [31] investigated complexes of bromophenol with methyl derivatives of pyridine in chlorobenzene. The obtained data correspond to $-\Delta H^{\circ}$ in the range $12-38 \mathrm{~kJ} \cdot \mathrm{mol}^{-1}$ and $-\Delta S^{\circ}$ in the range $29-55 \mathrm{~J} \cdot \mathrm{mol}^{-1} \cdot \mathrm{K}^{-1}$. The values of thermodynamic parameters for the complexes of chlorophenols with TBA [29] are comparable with those of nitrophenol.

From the studies $[29,37-44]$ it follows that the concentration of the PT form, independently of the H-bonding type, increases with an increase of $\Delta p K_{a}$ value of interacting components, as well as with increase of the solvent activity and the drop of temperature.

For the systems with negative or close to zero $\Delta p K_{a}$ values, it was not possible to find traces of the PT band even in the most active solvents at temperatures as low as below $-190^{\circ} \mathrm{C}$ [38]. Thus, for observation in UV spectrum participation of the PT form even in favorable conditions (low temperature and high polarity of solvent), some boundary $\Delta p K_{a}$ value is necessary.

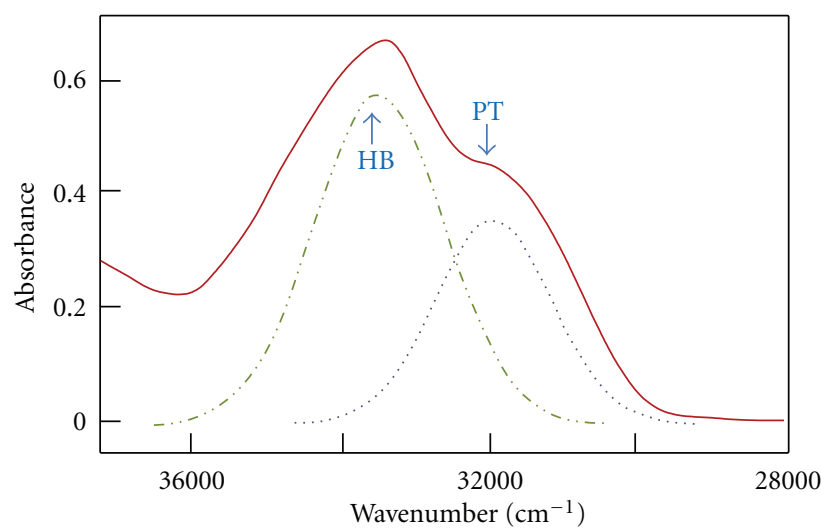

FIGURE 11: The plot of the absorbance versus wavenumber for 2,4,6-trichlorophenol in tributylamine at room temperature, $c=$ $5 \cdot 10^{-4} \mathrm{~mol} \cdot \mathrm{dm}^{-3} ; d=5 \mathrm{~mm}$.

Figure 12 shows the UV spectra for the series of complexes formed by TBA with various chlorophenols of increasing acidity. It can be seen that 2,4-dichlorophenol and 2,4,5-trichlorophenol do not show any contributions of PT species, only 2,6-dichlorophenol shows traces of the ionic PT form. For 2,4,6-trichlorophenol, a considerable amount (ca. 25\%) of the PT form was estimated from the UV spectrum. Pentachlorophenol appears entirely in the zwitterionic state, whereas in a case of 2,6-dichloroand 2,4,5-trichloro derivatives, characterized by almost the same $\Delta p K_{a}$ values, some contribution of the PT state shows only the former one. The $\Delta p K_{a}$ value is not, however, a completely satisfactory measure of the proton donoracceptor properties in nonaqueous media.

In several papers, for example, [45-48] one considers the attention that one should apply another scale of proton donor and acceptor properties for defining the proton 


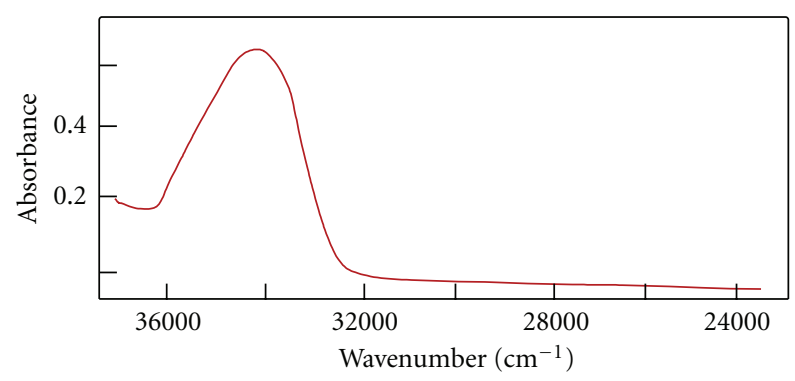

(a)

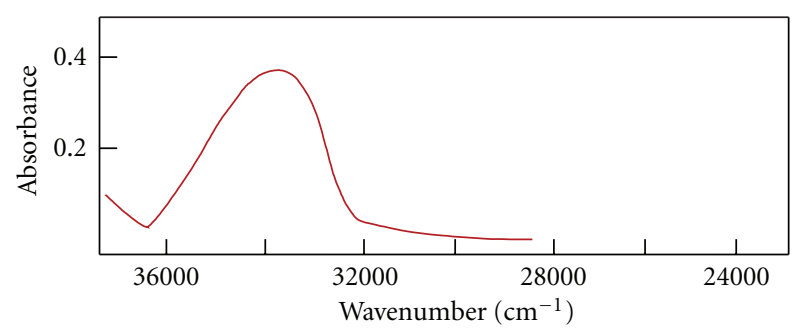

(b)

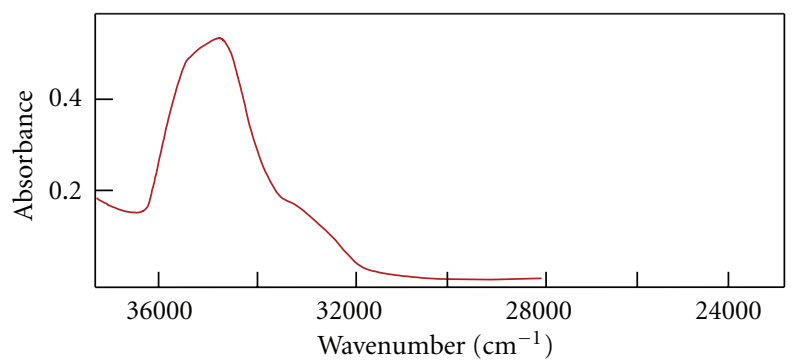

(c)

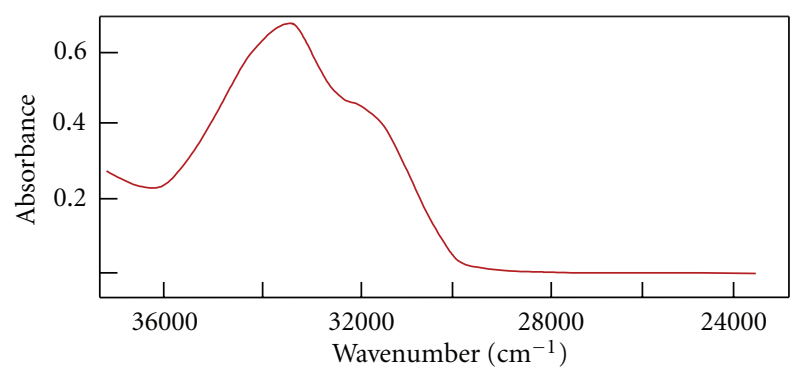

(d)

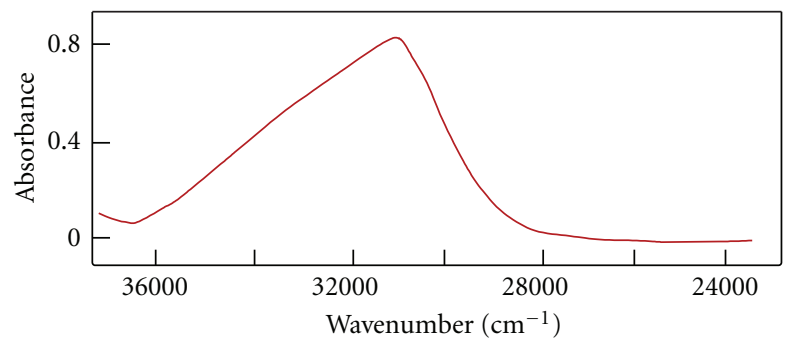

(e)

FIGURE 12: UV spectra of chlorophenols: (a) 2,4-dichlorophenol, (b) 2,4,5-trichlorophenol, (c) 2,6-dichlorophenol, (d) 2,4,6-trichlorophenol, (e) pentachlorophenol in TBA at room temperature, $c=5 \cdot 10^{-4} \mathrm{~mol} \cdot \mathrm{dm}^{-3} ; d=5 \mathrm{~mm} \mathrm{[29].}$

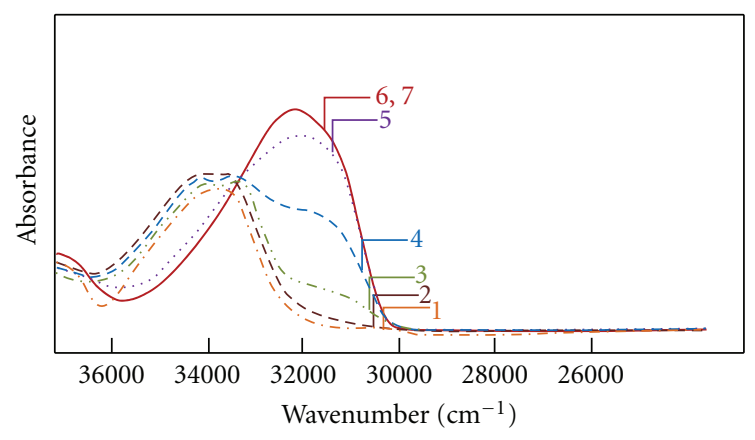

FIGURE 13: UV spectra of 2,4-dichlorophenol in TBA as a function of temperature: $298 \mathrm{~K}(1), 223 \mathrm{~K}(2), 203 \mathrm{~K}$ (3), $186 \mathrm{~K}(4), 165 \mathrm{~K}$ (5), $143 \mathrm{~K}(6), 128 \mathrm{~K}(7) . C=4 \times 10^{-4} \mathrm{~mol} \mathrm{dm}^{-3}, d=5 \mathrm{~mm}$, wavenumber of PT form $\cong 32160 \mathrm{~cm}^{-1}$ and $\mathrm{HB}$ form $\cong 33840 \mathrm{~cm}^{-1}$ [29].

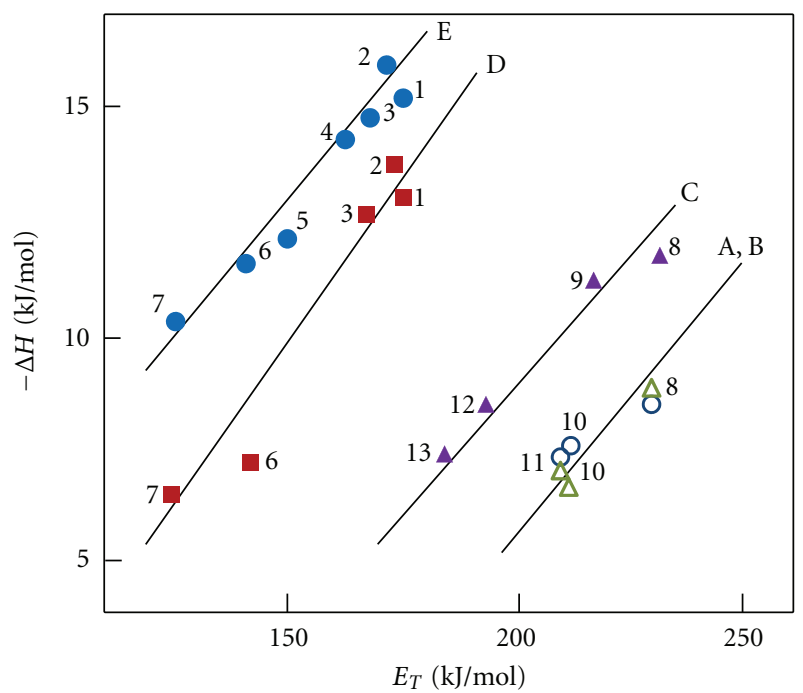

FIgURE 14: Comparison of the $\Delta H_{\mathrm{PT}}^{\circ}$ with $E_{T}$ parameters for Mannich bases: (A) 2-(N,N-dimethylaminomethyl)-4,6-dibro- mophenol, (B) 2-(N,N-diethylaminomethyl)-4-nitro-phenol, (C) 2(N,N-diethylaminomethyl)-3,4,6-trichlorophenol, (D) 2-(N,N-diethylaminomethyl)-3,4,5,6-tetrachlorophenol, (E) 2-(N,N-diethylaminomethyl)-4-nitronaphthol-1, in 1,2-dichloroethane (1), dichloromethane (2), n-butylchloride (3), chloroform (4), 1,4-dioxane (5), isopropylbenzene (6) squalane (7), methanol (8), ethanol (9), butan-1-ol (10), propan-1-ol (11), acetonitrile (12), and N,Ndimethylformamide (13) [36].

position in hydrogen-bonded complexes. In the analysis, one takes into account the proton affinity and deprotonation enthalpy based on calculations by using DFT methods. However, in the present article, we limited our considerations to experimental methods leading to evaluation of the $p K_{a}$ values.

A strong influence of cooling on the increase of concentration of the PT form indicates on negative change of enthalpy effect on the proton transfer process. In Figure 13, the UV spectra of 2,4-dichlorophenol in TBA are shown as a function of temperature [29]. The 2,4-dichlorophenolTBA system at room temperature does not show any 
contribution of the PT state. Similar to other systems of this type, we observe a very strong influence of cooling on the contribution of the PT state. At the temperatures 203, 186 , and $165 \mathrm{~K}$, the values of $K_{\mathrm{PT}}$ are $0.33,0.82$, and 5.70 , respectively. The complete proton-transfer state is reached at about $143 \mathrm{~K}$ and further cooling does not affect the intensity of the phenolate band.

By using electronic spectroscopy in the UV range, the PT equilibrium constants have been measured as a function of temperature in various solvents for various $\mathrm{H}$-bonded systems. They allowed to determine the thermodynamic parameters of the PT process and correlate with various empirical parameters of the solvent activity. The results for Mannich bases [36, 39, 40] correlated with the DimrothReichardt $E_{T}$ parameter $[49,50]$ are presented in Figure 14. These correlations present individual straight lines with similar slope for particular Mannich bases. Such clear differentiation shows that the differences in the proton affinity of particular acid-base centers contribute essentially to the stabilization of both forms. The observed effect of solvent activity shows that the proton transfer process is characterized by two factors. Simultaneously, with previous $\Delta p K_{a}$ effect that can be classified as inter one, an additional factor, called an external, takes place, which correlates with the solvent activity expressed by the $E_{T}$ parameter. Formally, one can express

$$
\Delta H_{\mathrm{PT}}^{\circ}=\Delta H_{\mathrm{int}}^{\circ}\left(\Delta p K_{a}\right)+\Delta H_{\mathrm{ext}}^{\circ}\left(E_{T}\right),
$$

however, quantitative estimation of both components is not an easy task.

The attempt has been undertaken to correlate the $\Delta H_{\mathrm{PT}}^{\circ}$ values with other parameters characterized the solvent activity, but the best correlation was obtained with $E_{T}$. Thus, the external factor contains two effects, that is, the electrostatic stabilization of the ionic form and the donoracceptor interaction of solvent molecules with the free electron pair of the phenolate oxygen atom. So far, no proton transfer equilibrium was observed in the gas phase that prooves decisive role of the solvent for observation of the proton transfer. This is confirmed by relatively high values of entropy effect, $\Delta S_{P T}^{\circ}$ from -30 up to $-70 \mathrm{~J} \mathrm{~K}^{-1} \mathrm{~mol}^{-1}$ $[36,39,40]$ that confirms a considerable redistribution of molecules and high increase of ordering of solvent molecules under influence of intramolecular proton transfer.

The UV spectra were used to locate the position of 50\% proton transfer in chloranilic acid-amine complexes; the similar result was deduced from IR and NMR studies [51]. Chranina et al. [52] studied the proton transfer equilibria between hydroxyanthraquinone dyes and aliphatic amines in low-polarity solvents by UV spectroscopy. The shift of this equilibrium in an external electrical field has been observed by the method of electrochromism in the visible region. Also, the mechanism of proton transfer reactions between various acids and amines was studied kinetically by applying UV spectroscopy, when the order and the isotopic ratio effect were discussed $[53,54]$.

\section{Vibrational Polarization of Hydrogen Bonded Systems}

It has been broadly postulated by Zundel [55] that for the characteristic dependences of the important physical parameters on $\Delta p K_{N}$, with the anomalous behavior in the critical region, the large proton polarizability of the hydrogen bonds is responsible. The extraordinary increase in proton polarizability with increased strength of the hydrogen bonds in heteroconjugated systems was the aim of detailed infrared studies conducted by Hawranek's group. For six systems of pentachlorophenol $(\mathrm{PCPh})$ dissolved in different basis, the molar vibrational polarization ( $P^{\text {vib }}$, called also atomic polarization as it arises from atomic motions) and molar electronic polarization were determined according to the procedure sketched below. Names of the basis are given in Table 1. The PCPh-base complexes were studied in binary solutions, that is, the proton donor $(\mathrm{PCPh})$ was directly dissolved in an excess of the proton acceptor. Such conditions facilitated accurate determination of optical quantities necessary for calculations of the $P^{\text {vib }}$ values, according to the following scheme.

Table 1 shows the $P_{2}^{\text {vib }}$ values along with the position $\left(\nu_{\max }\right)$ and the half width $\left(\Delta \nu_{1 / 2}\right)$ of the $v_{s}(\mathrm{OH})$ band. The spectral parameters were obtained only for $\mathrm{H}$-bonded systems related to the nonproton-transfer state, their values cannot be estimated with a sufficient accuracy for systems corresponding to other two states (see Figure 2). The plot of the $P_{2}^{\text {vib }}$ values versus $\Delta p K_{a}$, shown in Figure 15, possess the delta type character with a maximum.

It has to be mentioned here that the measurements in binary system have many advantages that facilitate the used procedure of determination of the molar vibrational polarization. However, there is also one disadvantage: the $P^{\text {vib }}$ values are obtained for $\mathrm{H}$-bonded systems differently polarized by their environment. The $\mathrm{PCPh}$-base complexes are immersed in various media that have different macroscopic parameters and more or less strongly polarize the hydrogen bonds. For each system, the $\xi$ and $\Delta p K_{a}$ (crit) parameters should be determined whenever the $\Delta p K_{a}$ values are subjected to the normalization procedure. Due to the lack of such data, the $P^{\text {vib }}$ values on Figure 15 are plotted against $\Delta p K_{a}$ parameter. We can guess that the normalization and the different influence of solvents on the vibrational polarization should not meaningfully change the delta-type relation between $P^{\mathrm{vib}}$ and strength of the hydrogen-bonded systems.

According to Table 1, the molar vibrational polarization increases from a very small value for $\mathrm{TMPh}$ in inert $\mathrm{CCl}_{4}$ solution, to a slightly larger for the $\mathrm{OH}$ group involved in a weak $\mathrm{OH} \cdots \mathrm{Cl}$ intramolecular hydrogen bond in $\mathrm{PCPh}$. Noticeable increase is observed for $\mathrm{OH}$ group engaged in a weak intermolecular hydrogen bonds in the $\mathrm{PCPh}-\mathrm{CH}_{3} \mathrm{CN}$ and $\mathrm{PCPh}$-dioxane systems. Their $P^{\mathrm{vib}}$ values compared with that for the 2,4,6-TMPh-CCl 4 indicate on the 17- and 20-fold increase. The changes are strictly correlated with the typical spectral features of H-bond formation, that is, the shift of $v_{s}(\mathrm{OH})$ bands towards lower frequencies and the increase in its bandwidth. In relation to the system with intramolecular 
TABLE 1: Spectral parameters related to the $v_{s}(\mathrm{OH})$ band and $P^{\mathrm{vib}}$ of the H-bond complexes of PCPh.

\begin{tabular}{|c|c|c|c|c|}
\hline Acceptor & $\nu_{\max }\left(\mathrm{cm}^{-1}\right)$ & $\Delta v_{1 / 2}\left(\mathrm{~cm}^{-1}\right)$ & $P^{\text {vib }}\left(\mathrm{cm}^{3} \mathrm{~mol}^{-1}\right)$ & Reference \\
\hline $\mathrm{CCl}_{4}$ & 3525 & 21.6 & 0.048 & {$[56]$} \\
\hline $\mathrm{CH}_{3} \mathrm{CN}$ & 3322 & 275.5 & 0.294 & {$[57]$} \\
\hline Dioxane- $\mathrm{D}_{8}$ & 3162 & 316.5 & 0.333 & {$[58]$} \\
\hline 3-Chloropyridine & 2737 & 945 & 1.182 & [59] \\
\hline Pyridine & - & - & 12.5 & {$[60]$} \\
\hline 2,4,6-Trimethylpyridine & - & - & 17. 8 & {$[61]$} \\
\hline Tri-n-octylamine & - & - & 9.0 & {$[62]$} \\
\hline 2,4,6-TMPh-CCl & 3622 & & 0.017 & {$[56]$} \\
\hline
\end{tabular}

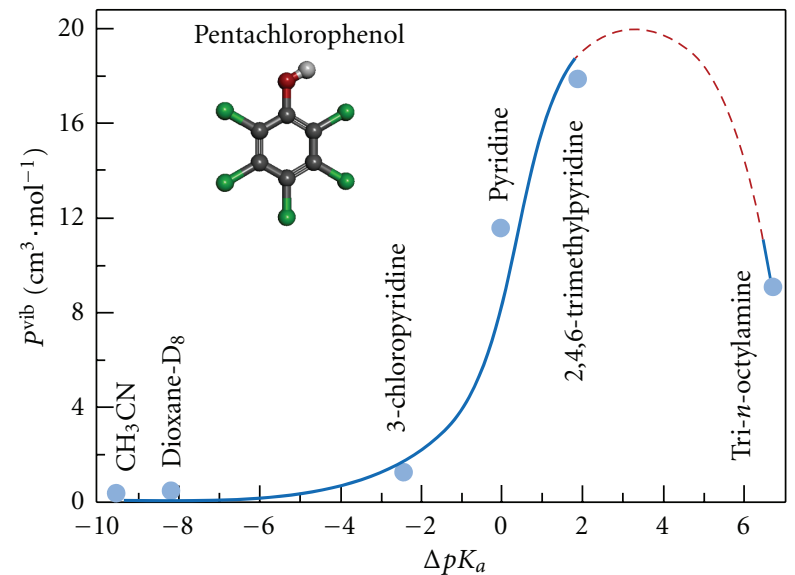

Figure 15: $P^{\text {vib }}$ plotted versus $\Delta p K_{a}$ of complexes formed by PCPh with various proton acceptors.

hydrogen bonds $\left(\mathrm{PCPh}_{-} \mathrm{CCl}_{4}\right)$, the increase is 6-fold for the $\mathrm{PCPh}-\mathrm{CH}_{3} \mathrm{CN}$ and 7 -fold for the PCPh-dioxane complex. It reveals that formation even rather weak intermolecular $\mathrm{H}$-bond, when the proton is located in a relatively narrow single-minimum proton potential near the acid (Figure 1 (1)), leads to a drastic increase in $\mathrm{P}^{\mathrm{vib}}$ of the $\mathrm{OH}$ group.

The PCPh-3-chloropyridine system, with still relatively asymmetrical hydrogen bond, is close to a border between the $\mathrm{HB}$ and the PT equilibrium states (see Figure 2). However, its $P^{\text {vib }}$ value, compared with that obtained for the system with intramolecular $\mathrm{H}$-bonded, shows almost 25- and 70-fold increase in comparison with the free $\mathrm{OH}$ group in the 2,4,6-TMPh- $\mathrm{CCl}_{4}$ system. Despite this, the molar vibrational polarization of the $\mathrm{PCPh}-3$-chloropyridine system is still markedly less than its molar electronic polarization.

The complex of PCPh with pyridine with symmetrical $\mathrm{O} \cdots \mathrm{H} \cdots \mathrm{N}$ hydrogen bond is classified to the proton transfer state. The molar vibrational polarization of the $\mathrm{OH}$ group rises to $12.5 \mathrm{~cm}^{3} \cdot \mathrm{mol}^{-1}$. This value compared with that obtained for free $\left(2,4,6-\mathrm{TMPh}-\mathrm{CCl}_{4}\right)$ and for the intramolecularly bonded ( $\left.\mathrm{PCPh}-\mathrm{CCl}_{4}\right) \mathrm{OH}$ group shows almost 600- and 200-fold increase, respectively.

According to [28], the complex of PCPh with 2,4,5trimethylpyridine is close to the border between the PT equilibrium and the PT states. Its molar vibrational polarization is more than 370 and 1000 times higher than in the $\mathrm{PCPh}-\mathrm{CCl}_{4}$ and 2,4,6-TMPh- $\mathrm{CCl}_{4}$ system, respectively. For the PCPh-2,4,6-trimethylpyridine complex hydrogen bond possess largest proton polarizability. The last complex of PCPh with tri-n-octylamine belongs to the PT state. According to Figure 15, its $P^{\text {vib }}$ value drops almost twice when compared with the previous system. For such large change of $P^{\mathrm{vib}}$, a characteristic evolution of the infrared spectra corresponding to the PT state, shown in Figure 8, is responsible.

Summing up, the very large $P^{\text {vib }}$ values determined for $\mathrm{PCPh}$ complexes with pyridine and 3-chloropyridine are excellent confirmation of the extraordinary properties of hydrogen bonds from the transition region with symmetrical potential. Moreover, they confirm very well Zundel's concept that an extreme broadening of the $\mathrm{OH}$ band occurs for hydrogen bonds showing the largest proton polarizability [55].

\section{References}

[1] D. Hadži and H. W. Thompson, Eds., Hydrogen Bonding, Pergamon Press, London, UK, 1959.

[2] L. Pauling, The Nature of the Chemical Bond and the Structure of Molecules and Crystals: An Introduction to Modern Structural Chemistry, Cornell University Press, Ithaca, NY, USA, 1960.

[3] G. C. Pimentel and A. L. McClellan, The Hydrogen Bond, W. H. Freeman, San Francisco, Calif, USA, 1960.

[4] S. N. Vinogradov and R. H. Linnel, Hydrogen Bonding, Van Nostrand-Reinhold, New York, NY, USA, 1971.

[5] M. D. Joesten and L. J. Schaad, Hydrogen Bonding, Marcel Dekker, New York, NY, USA, 1974.

[6] P. Schuster, G. Zundel, and C. Sandorfy, Eds., The Hydrogen Bond. Recent Developments in Theory and Experiments, vol. 13, North Holland, Amsterdam, The Netherlands, 1976.

[7] H. Ratajczak and W. J. Orwille-Thomas, Eds., Molecular Interactions, John Wiley \& Sons, New York, NY, USA, 1980.

[8] P. L. Huyskens, W. A. P. Luck, and Th. Zeegers-Huyskens, Eds., Intermolecular Forces: An Introduction to Modern Methods and Results, Springer, Heidelberg, Germany, 1991.

[9] S. Scheiner, Ed., Hydrogen Bonding. A Theoretical Perspective, Oxford University Press, Oxford, UK, 1997.

[10] G. A. Jeffrey, Introduction to Hydrogen Bonding, Oxford University Press, Oxford, UK, 1997.

[11] D. Hadži, Ed., Theoretical Treatments of Hydrogen Bonding, Oxford University Press, Oxford, UK, 1997. 
[12] G. R. Desiraju and T. Steiner, The Weak Hydrogen Bond in Structural Chemistry and Biology, Oxford University Press, Oxford, UK, 1999.

[13] Th. Elsaesser and H. J. Bakker, Eds., Ultrafast Hydrogen Bonding Dynamics and Proton Transfer Processes in the Condensed Phase, Kluwer Academic Publishers, Dordrecht, The Netherlands, 2002.

[14] S. J. Grabowski, Ed., Hydrogen Bonding-New Insights, Springer, Dordrecht, The Netherlands, 2006.

[15] Y. Maréchal, The Hydrogen Bond and the Water Molecule: The Physics and Chemistry of Water Aqueous and Bio-Media, Elsevier, Amsterdam, The Netherlands, 2007.

[16] G. Gilli and P. Gilli, The Nature of The Hydrogen Bond: Outline of a Comprehensive Hydrogen Bond Theory, Oxford University Press, Oxford, UK, 2009.

[17] P. L. Huyskens and Th. Zeegers-Huyskens, "Associations moleculaires et equilibres acide-base," Journal de Chimie Physique, vol. 61, aticle 84, 1964.

[18] P. Huyskens, L. Sobczyk, and I. Majerz, "On a hard/soft hydrogen bond interaction," Journal of Molecular Structure, vol. 615, no. 1-3, pp. 61-72, 2002.

[19] L. Sobczyk, "Softness of hydrogen bond interaction," Khimicheskaya Fizika, vol. 24, article 31, 2005.

[20] L. Sobczyk, "Quasi-symmetric O-H * . N hydrogen bonds in solid state," Molecular Physics Reports, vol. 14, pp. 19-31, 1996.

[21] R. Nouwen and P. Huyskens, "Dipole moments and structure of the complexes of phenols with pyridines," Journal of Molecular Structure, vol. 16, no. 3, pp. 459-471, 1973.

[22] S. N. Smirnov, N. S. Golubev, G. S. Denisov, H. Benedict, P. Schah-Mohammedi, and H. H. Limbach, "Hydrogen/deuterium isotope effects on the NMR chemical shifts and geometries of intermolecular low-barrier hydrogen-bonded complexes," Journal of the American Chemical Society, vol. 118, no. 17, pp. 4094-4101, 1996.

[23] E. Grech, J. Kalenik, and L. Sobczyk, " ${ }^{35} \mathrm{Cl}$ nuclear quadrupole resonance studies of pentachlorophenol-amine hydrogenbonded complexes," Journal of the Chemical Society, Faraday Transactions 1, vol. 75, pp. 1587-1592, 1979.

[24] J. P. Castaneda, G. S. Denisov, and V. M. Schreiber, "Structure of $1: 1$ and $1: 2$ complexes formed by aromatic $\mathrm{NH}$ and $\mathrm{OH}$ proton donors with aliphatic amines. Possibility of homoconjugated $\mathrm{NHN}^{+}$cation formation," Journal of Molecular Structure, vol. 560, no. 1-3, pp. 151-159, 2001.

[25] I. Majerz, Z. Malarski, and L. Sobczyk, "Proton transfer and correlations between the $\mathrm{C}-\mathrm{O}, \mathrm{O}-\mathrm{H}, \mathrm{N}-\mathrm{H}$ and $\mathrm{O} \cdots \mathrm{N}$ bond lengths in amine phenolates," Chemical Physics Letters, vol. 274, no. 4, pp. 361-364, 1997.

[26] Z. Malarski, M. Roepenk, E. Grech, and L. Sobczyk, "Dielectric and spectroscopic studies of pentachlorophenol-amine complexes," Journal of Physical Chemistry, vol. 86, no. 3, pp. 401406, 1982.

[27] J. Kalenik, I. Majerz, L. Sobczyk, E. Grech, and M. M. M. Habeeb, "Infra-red and ${ }^{35} \mathrm{Cl}$ nuclear quadrupole resonance studies of hydrogen bonded adducts of 2-chlorobenzoic acid derivatives," Collection of Czechoslovak Chemical Communications, vol. 55, no. 1, pp. 80-90, 1990.

[28] G. Albrecht and G. Zundel, "Phenol-amine hydrogen bonds with large proton polarizabilities. Position of the $\mathrm{OH} \cdots \mathrm{N}$ $\rightleftharpoons \mathrm{O}^{--} \cdots \mathrm{H}^{+} \mathrm{N}$ equilibrium as a function of the donor and acceptor," Journal of the Chemical Society, Faraday Transactions 1, vol. 80, no. 3, pp. 553-561, 1984.
[29] V. M. Schreiber, A. Kulbida, M. Rospenk, L. Sobczyk, A. Rabold, and G. Zundel, "Temperature effect on protontransfer equilibrium and IR spectra of chlorophenol-tributylamine systems," Journal of the Chemical Society, Faraday Transactions, vol. 92, no. 14, pp. 2555-2561, 1996.

[30] H. Baba, A. Matsuyama, and H. Kokubun, "Proton transfer in p-nitrophenol-triethylamine system in aprotic solvents," Spectrochimica Acta Part A, vol. 25, no. 10, pp. 1709-1722, 1969.

[31] J. E. Crooks and B. H. Robinson, "Hydrogen-bonded and ionpair complexes in aprotic solvents," Faraday Symposia of the Chemical Society, vol. 10, pp. 29-40, 1975.

[32] H. Romanowski and L. Sobczyk, "Ultraviolet spectra and proton-transfer equilibria in 2,6-dichloro-4-nitrophenolamine systems," Journal of Physical Chemistry, vol. 79, no. 23, pp. 2535-2542, 1975.

[33] M. M. Habeeb and M. A. Kharaba, "Intermolecular hydrogen bonds and proton transfer equilibrium in some nitro cresolsaliphatic amines-acetonitrile or methanol systems," Journal of Molecular Liquids, vol. 107, no. 1-3, pp. 205-219, 2003.

[34] M. M. Habeeb and R. M. Alghanmi, "Spectrophotometric study of intermolecular hydrogen bonds and proton transfer complexes between 1,2-dihydroxyanthraquinone and some aliphatic amines in methanol and acetonitrile," Journal of Chemical and Engineering Data, vol. 55, no. 2, pp. 930-936, 2010.

[35] Z. Dega-Szafran, E. Dulewicz, and M. Szafran, "Spectroscopic studies of $\mathrm{N}$-methylpiperidine betaine complexes with phenols," Journal of Molecular Structure, vol. 704, no. 1-3, pp. 155161, 2004.

[36] M. Rospenk, "The influence of steric effects of proton-transfer equilibrium in intramolecular hydrogen bonds," Journal of Molecular Structure, vol. 221, pp. 109-114, 1990.

[37] V. M. Schreiber, M. Rospenk, A. I. Kulbida, and L. Sobczyk, "Shaping of broad IR absorption in proton transfer equilibrating $\mathrm{OH} \cdot \cdots \cdot \mathrm{N}$ hydrogen bonded systems," Spectrochimica Acta-Part A, vol. 53, no. 12, pp. 2067-2078, 1997.

[38] V. M. Schreiber, A. Koll, and L. Sobczyk, "Effect of temperature on the proton transfer equilibrium in the intramolecular hydrogen bond hydroxyl - - nitrogen," Bulletin de l'Academie Polonaise des Sciences, Serie des Sciences Chimiques, vol. 26, article 651, 1978.

[39] A. Koll, M. Rospenk, and L. Sobczyk, "Thermodynamic parameters for the proton-transfer reaction in Mannich bases," Journal of the Chemical Society, Faraday Transactions 1, vol. 77, no. 10, pp. 2309-2314, 1981.

[40] M. Rospenk, I. G. Ruminskaya, and V. M. Schreiber, "Elektronnye spektri i wnutrimolekularnij perekhod protona $\mathrm{V}$ osnovanyakh Mannikha v zhidkikh i tverdikh stekloobraznikh rastvorakh," Journal of Applied Spectroscopy, vol. 36, article 756, 1982

[41] M. Rospenk, L. Sobczyk, A. Rabold, and G. Zundel, "Low temperature studies on ultraviolet and infrared spectra of ortho Mannich bases," Spectrochimica Acta-Part A, vol. 55, no. 4, pp. 855-860, 1999.

[42] I. Król-Starzomska, M. Rospenk, Z. Rozwadowski, and T. Dziembowska, "UV-visible absorption spectroscopic studies of intramolecular proton transfer in N-(R-salicylidene)-alkylamines," Polish Journal of Chemistry, vol. 74, no. 10, pp. 14411446, 2000.

[43] M. Rospenk, I. Król-Starzomska, A. Filarowski, and A. Koll, "Proton transfer and self-association of sterically modified Schiff bases," Chemical Physics, vol. 287, no. 1-2, pp. 113-124, 2003. 
[44] A. Koll, M. Rospenk, L. Sobczyk, and T. Glowiak, "Properties of a strong intramolecular $\mathrm{OHO}$ hydrogen bond in 2-(N,Ndiethylamino-N-oxymethyl)-4,6-dichlorophenol," Canadian Journal of Chemistry, vol. 64, no. 9, pp. 1850-1854, 1986.

[45] S. Kong, I. G. Shenderovich, and M. V. Vener, "Density functional study of the proton transfer effect on vibrations of strong (short) intermolecular $\mathrm{O}-\mathrm{H} \cdot \cdots \mathrm{N} / \mathrm{O}^{-} \cdots \mathrm{H}-\mathrm{N}^{+}$ hydrogen bonds in aprotic solvents," Journal of Physical Chemistry A, vol. 114, no. 6, pp. 2393-2399, 2010.

[46] T. Lankau and C. H. Yu, "Solubility of methane in water: The significance of the methane-water interaction potential," Chemical Physics Letters, vol. 424, article 264, 2006.

[47] P. Gilli, L. Pretto, and G. Gilli, "PA/pKa equalization and the prediction of the hydrogen-bond strength: a synergism of classical thermodynamics and structural crystallography," Journal of Molecular Structure, vol. 844-845, pp. 328-339, 2007.

[48] T. Lankau and C. H. Yu, "Correlated proton motion in hydrogen bonded systems: tuning proton affinities," Physical Chemistry Chemical Physics, vol. 9, no. 2, pp. 299-310, 2007.

[49] C. Reichardt, "Empirical parameters of the polarity of solvents," Angewandte Chemie International Edition in English, vol. 4, no. 1, pp. 29-40, 1965.

[50] C. Reichardt and K. Dimroth, "Solvents and empirical parameters for characterization of their polarity," Fortschritte der Chemischen Forschung, vol. 11, article 1, 1968.

[51] M. Habeeb, H. Alwakil, A. El-Dissouky, and H. Abdel-Fattah, "Spectroscopic studies of 1:1 chloranilic acid-amine complexes," Polish Journal of Chemistry, vol. 69, article 1428, 1995.

[52] O. V. Chranina, F. P. Czerniakowski, and G. S. Denisov, "UV-vis electrochromism due to proton transfer," Journal of Molecular Structure, vol. 177, pp. 309-315, 1988.

[53] W. Galezowski and A. Jarczewski, "Kinetics, isotope effects of the reaction of 1-(4-nitrophenyl)-1-nitroalkanes with DBU in tetrahydrofuran and chlorobenzene solvents," Canadian Journal of Chemistry, vol. 68, no. 12, pp. 2242-2248, 1990.

[54] A. Jarczewski, G. Schroeder, and K. T. Leffek, "The proton transfer reaction between bis(2,4-dinitrophenyl)methane and nitrogen bases in dimethyl sulfoxide and toluene solvents," Canadian Journal of Chemistry, vol. 69, no. 3, pp. 468-473, 1991.

[55] G. Zundel, "Hydrogen bonds with large proton polarizability and proton transfer processes in electrochemistry and biology," Advances in Chemical Physics, vol. 111, 2000.

[56] J. P. Hawranek and B. Czarnik-Matusewicz, "Infrared dispersion of H-bonded systems. The dielectric function for weak complexes," Chemical Physics Letters, vol. 109, no. 2, pp. 166169, 1984.

[57] J. P. Hawranek and B. Czarnik-Matusewicz, "Infrared dispersion of the H-bonded pentachlorophenol-acetonitrile complex," Chemical Physics Letters, vol. 138, no. 5, pp. 397-400, 1987.

[58] J. P. Hawranek and B. Czarnik-Matusewicz, "IR dispersion of hydrogen bonded systems III. Pentachlorphenol-dioxaneD8 complex," Journal of Molecular Structure, vol. 143, no. C, pp. 337-340, 1986.

[59] B. Czarnik-Matusewicz and J. P. Hawranek, "Infrared dispersion of the hydrogen-bonded pentachlorophenol-3-chloropyridine complex," Journal of Molecular Structure, vol. 219, pp. 221-226, 1990.

[60] J. P. Hawranek, B. Czarnik-Matusewicz, and W. Wrzeszcz, "Infrared dispersion of the hydrogen-bonded pentachlorophenol-pyridine complex," Journal of Molecular Structure, vol. 322, pp. 181-186, 1994.
[61] J. P. Hawranek, J. Z. Flejszar-Olszewska, and A. S. Muszynski, "Infrared dispersion of the pentachlorophenol-sym-collidine complex," Journal of Molecular Structure, vol. 448, no. 2-3, pp. 149-159, 1998.

[62] J. P. Hawranek and A. S. Muszynski, "Infrared dispersion of the pentachlorophenol-trioctylamine complex," Journal of Molecular Structure, vol. 552, no. 1-3, pp. 205-212, 2000. 

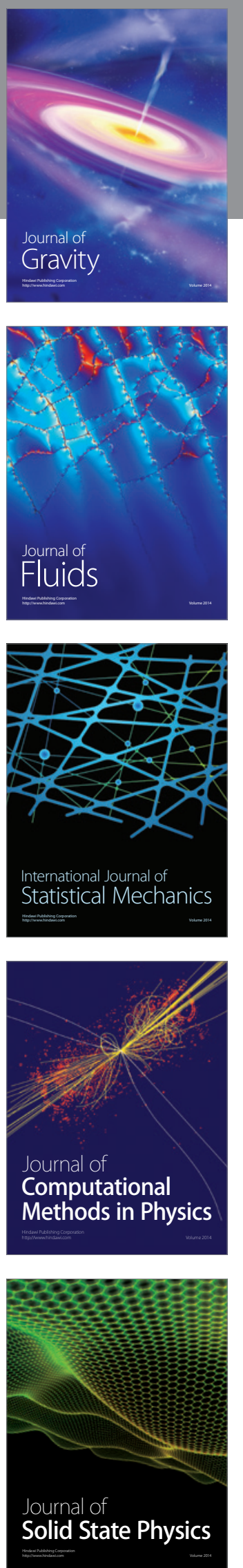

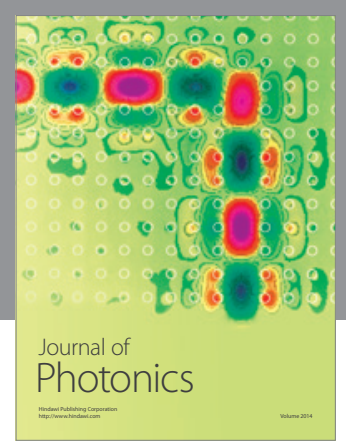

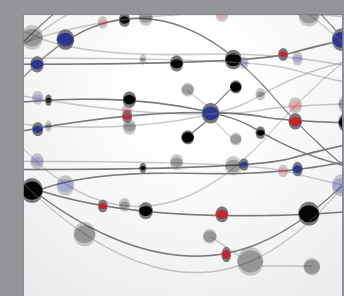

The Scientific World Journal
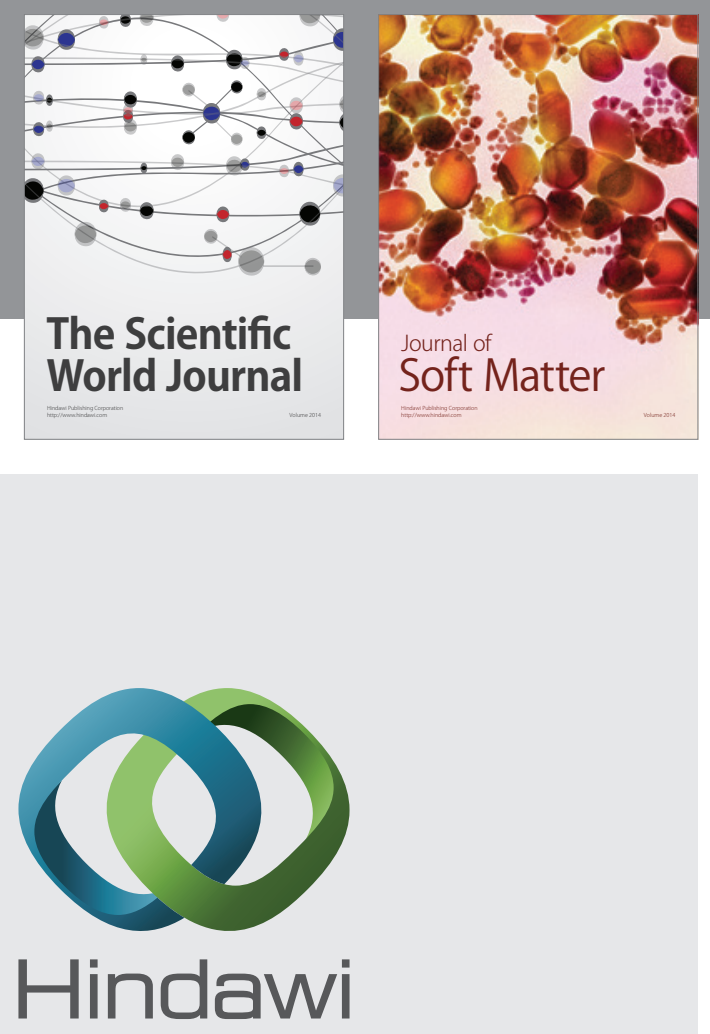

Submit your manuscripts at

http://www.hindawi.com
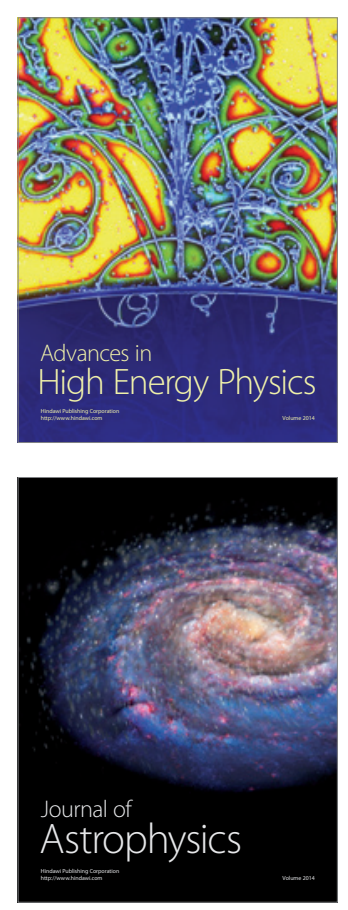
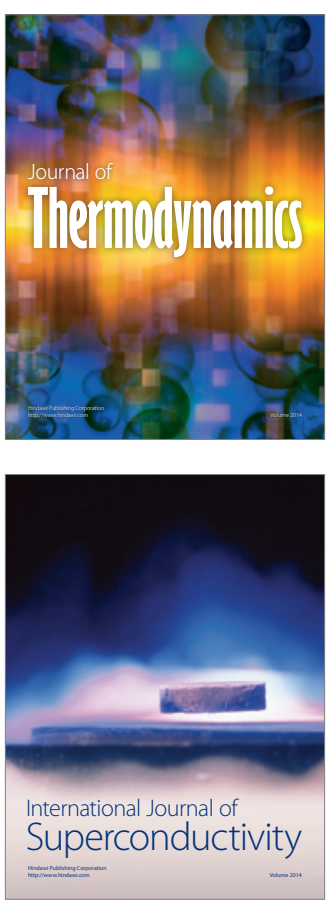
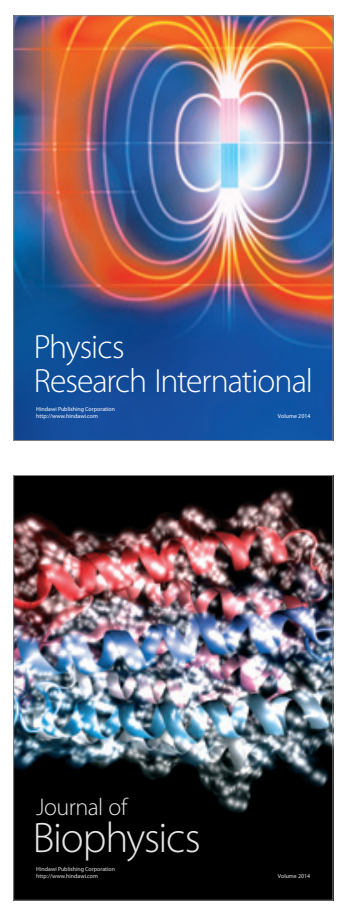
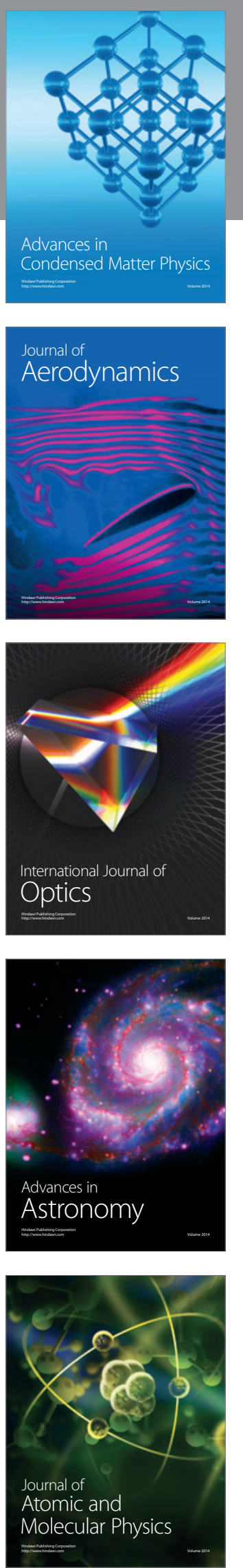